groups has been supplemented by an analysis of the available demographic data relating to the various groups in the territory.

As regards East Africa, efforts to obtain material from Government sources have so far been disappointing. Dr. Meinhard has almost completed the detailed analysis of the published literature relating to the Nyamwezi group of tribes in Tanganyika, which will be circulated to the Government and other persons in the hope of eliciting further data. Dr. Mayer has prepared preliminary schedules for some smaller groups of tribes in East Africa.

In South Africa and the High Commission Territories the schemes for the collation of material have not yet reached the productive stage; arrangements for the organization of material in South East Africa, the Rhodesias, and Nyasaland were suspended pending Dr. Gluckman's visit to England this summer, and information concerning the details of the plans of field research organized by the Rhodes-Livingstone Institute.

\title{
Research in and for French Africa
}

IN 1943-4 the French Government established an Office of Scientific Colonial Research for the purpose of creating the scientific equipment necessary to the industrial and economic development of France Overseas. It aims at the training of specialized researchers and the organization of centres of research. Until its own institutes can be built and manned the Office is using eight existing centres in France, and another for the training of geographers and ethnographers will, it is expected, be opened in November this year. The course of study covers two years, the first of which will be spent by students in France and the second in Africa. It is planned to have in each group or federation of the colonies an autonomous research institute financed by the central Office and the local government. One will be set up in Madagascar, one at Brazzaville for Equatorial Africa, and the existing Institute at Dakar (IFAN) will be reorganized to fit into the scheme. Within the Office a committee will be formed to bring together the heads of these institutes in order to elaborate a general plan applicable to the whole continent. At Abijan on the Ivory Coast an Intercolonial Institute is to be erected where the second-year students will complete their training and where special studies on acclimatization and other subjects will be carried on.

The Report of the Office for 1945 records the expenditure of about two million francs for the support of thirty-nine research assistants in various French institutions; and also the establishment of friendly relations with many foreign scientific organizations, including the International African Institute. A long list of the subjects taught in the Centres is given: entomology, pedology, vegetal pathology, oceanography, geology, \&c. Ethnology was to be added in 1946. Various research projects were set afoot this year; one, under M. Aubert, to study soils in Senegal; another to study native medicinal plants. Other investigations include one of the transmission of heat through walls with a view to determining the most comfortable form of house in the tropics, using local materials to the maximum extent. M. Leroy went out to study the effect of humidity on the human organism; M. Mangenot to study 'swollen root' in the cacao-tree. Great attention has been paid to the preparation of maps showing density of population. In 1945 a committee of Human Studies was appointed under the presidency of Professor Rivet. M. Darot was put in charge of linguistic research and is studying Nilotic languages and their relation to those of Senegal. A ten years' plan has been formulated to cost a milliard and a half francs, including grants of I 50 millions for IFAN, of 108 millions for the Centrafrican Institute, of 85 millions for the Institute at Abijan, and of $\times 26$ millions for the metropolitan training centres.

\section{Research in the Cameroons}

Dr. Phyllis Kaberry, who has been engaged on a field-study of the economic position of women in the Bamenda division of the Cameroons, has completed her first tour and will 